\title{
Distrust And Dominance In Managing Alternative Work Arrangements: A Micro-Analytic Test Of Transaction Cost Theory
}

Terry R. Adler, (E-mail: tadler@nmsu.edu), New Mexico State University Gabriel D. Isaacs (E-mail: gisaacs@nmsu.edu ), New Mexico State University Robert L. Steiner, (E-mail: rsteiner@nmsu.edu),New Mexico State University

\begin{abstract}
Organizations that successfully outsource may see better value-creation in creating a sustainable competitive advantage. The objectives of this study were threefold: a) provide a framework for studying the effects of perceived distrust that leads to dominance, $b$ ) analyze how opportunism parlays into the concept of dominance, and c) determine if the relationship between outsource partners varies by analyzing transaction characteristics. Our research shows that firms should take caution to fully understand the effects that contract size has on a firm's resources.
\end{abstract}

\section{INTRODUCTION}

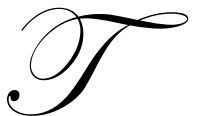

he 'Big Dig' in Boston, Massachusetts highlights the difficulty of managing outsource relationships through alternative work arrangements in the construction industry. For instance, PM Network (2004) stated that the 'Big Dig' contract costs will eventually grow from an estimated $\$ 2.6$ billion to $\$ 14.6$ billion. Maybe some of this cost growth can be attributed to opportunism by suppliers in the 'Big Dig' contract. Business Week's (2006) lead article also highlights some of the opportunities and difficulties in outsource partnerships. A key issue in outsourcing is the extent firms exert opportunism in the outsource contract, or alternative work arrangement, that in some cases make them more dominant? The assumption behind this question is that firms can govern other firms through alternative work arrangements to the point that integration and control is either captured, surrendered, or balanced. Firms adept at managing alternative work arrangement conditions would then be in a favorable exchange position to control the transaction more relative to their trading partner(s) (see Table 1 for a summary of the dominance literature relative to alternative work arrangements).

\section{THE USE OF ALTERNATIVE WORK ARRANGEMENTS}

The use of contracts, or alternative work arrangements, is an understudied area of strategic management, especially with regard to how firms decide what work to keep in-house, what work to outsource, and how they can control these transactions, if at all, through the contract. Our definition of dominance, therefore, takes on a structural emphasis consistent with the use of contracts (Williamson, 1975; 1985). Dominance in the contracting sense is different than traditional views of market dominance (see Table 1) as monopolistic firms may not be able to be dominant in every transaction because transactions can be unique depending on the degree of uncertainty, bounded rationality, asset specificity, and opportunism present. The alternative work arrangement could represent a level playing field where dominance becomes relevant to the transaction not the size of market share 
Table 1: Dominance and Alternative Work Arrangements in the Literature

\begin{tabular}{|c|c|c|}
\hline Topic & Finding & Author(s) \\
\hline \multirow{3}{*}{ Market Dominance } & Firm Performance Outcomes \& Mergers & $\begin{array}{l}\text { George \& Jacquemin (1972); Geroski \& Jacquemin } \\
\text { (1984); Yang (2002) }\end{array}$ \\
\hline & Strategic Competitive Analysis & D’Aveni (1999); Pass \& Lowes (1992); Riordan (1998) \\
\hline & Small Market Share & $\begin{array}{l}\text { Cheung \& Wang (1994); Roulac (2000); Schoenwald } \\
\text { (1997); Solow (1998) }\end{array}$ \\
\hline \multirow{9}{*}{ Strategic Advantage } & \multicolumn{2}{|c|}{ Alternative Work Arrangements relative to: } \\
\hline & Distrust & Adler (2000); Adler (2005) \\
\hline & General & Barthelemy \& Adsit (2003) \\
\hline & Research & Benfratello \& Sembenelli (2002) \\
\hline & Japanese OEMs & Blenkhorn \& Noori (1991) \\
\hline & Proprietary technology & Boswell (2000) \\
\hline & Quality in the value chain & Paladino, Bates \& de Silveira (2002) \\
\hline & Modular organizational forms & Schilling \& Steensma (2001) \\
\hline & Team performance & Zuckerman \& Higgins (2002) \\
\hline \multirow{4}{*}{ Strategic Outsourcing } & Multidimensional model & Anson (1988) \\
\hline & Engineering culture & Dannels (2000) \\
\hline & Information technology practices & Lacity \& Willcocks (1998) \\
\hline & Nonacademic settings & Odell \& Goswami (1985) \\
\hline
\end{tabular}

Following existing work on strategic behavior, we consider dominance in terms of the ability to exploit a strategic advantage at the expense of others (Geroski \& Jacquemin, 1984). Specifically, we suggest that dominance is defined as perceived partner opportunism in a transaction that provides a firm with supranormal economic returns. Since a firm is a nexus of contracts according to Williamson (1985) and these contracts most likely range from large to small in size, the larger the size of the resources committed to a contract, the more likely a partner firm is dominant in a particular transaction. Dominant firms should be able to exert pressure on other organizations since dominant firms have more control over the resources invoked through the contract to fulfill the transaction. Many times larger-sized contracts are used as a mechanism by firms to hide opportunistic elements that give them power over their trading partner. One result of larger contract size is that the contract becomes more hierarchical, or centralized, according to Stinchcombe's (1985) framework. Our definition of dominance thus reflects hierarchical control through non-traditional governance - alternative work arrangements.

\section{GOVERNANCE HYPOTHESES}

Government contractors, or sellers, are perceived to act as a dominant firm per our definition in the federal acquisition industry (Adler, 2000; Evanchik, 1989). Evanchik (1989) describes how the United States Air Force lacks the ability to pull back work into a hierarchy thus leaving but one option - to buy the development and procurement of military weapon systems. Thus, the government is limited from access to the full governance spectrum.

Most government managers and engineers recognize this situation and add contract provisions that drive up costs due to the perceived opportunism of government contractors. Unfortunately, many government contract writers do not read the "fine print" of the military specifications they feel are necessary to counter anticipated contractor opportunism. Table 1 describes how the government responded with generic MIL-PRIME specifications and standards to reduce the amount of contract requirements making contracts between the government and government contractors less hierarchical and, hopefully, less costly.

The unilateral relationship in government contracting is also affected by the information asymmetry created by military managers continually and consistently moving around the world. Following Kreps and Wilson (1980: 260) framework, government outsourcing is a microcosm ripe for dominant firms to flourish because no one has "the ability to foster a reputation." A summary of outsourcing is available at http://www.outsourcing.com//getstart/topten.html. We argue 
that firms will in fact become dominant through unwieldy and ambiguous contract provisions, capricious use of contract loopholes, and information asymmetry to generate large economic returns in typical transaction measures like cost, schedule and engineering changes.

H1: Dominant firm transactions will be significantly different from non-dominant firm transactions regarding the rate of:

$\mathrm{H}_{1 \mathrm{a}}$ : Cost Growth

$\mathrm{H}_{1 \mathrm{~b}}$ : Schedule Increases

$\mathrm{H}_{1 \mathrm{c}}$ : Number of Engineering Changes

\section{Alternative Work Arrangements}

Perceptions play a key role in how a firm uses their resources. Adler (2005) has found support for Lewicki et al.'s (1998) contention that states that in conditions of distrust, contractual requirements become more rigid and voluminous. Firms adept at manipulating the contract have an inherent advantage over firms less effective at contract management. Dominant firms can manipulate contractual changes that occur in the R\&D process by buffeting the perception of their own opportunism with their trading partner. Whether a bluff or not, since change is inevitable in R\&D, when a dominant firm sees an opportunity to change a contract requirement or extend a trading advantage, the dominant firm will capitalize on partner perceptions of opportunism and charge frequently and excessively.

A dominant firm will extract supranormal economic rents from their partner because their partner lacks adequate information to respond to contractual opportunism. An organization's inability to act contractually with their partner will be an economic liability that gives their partner dominance over them. The ability of dominant firms to overcharge relative to non-dominant firms, thus, formed the basis for the second and third hypotheses:

$\mathrm{H}_{2}$ : Dominant firm transactions will have higher daily cost growth than non-dominant firm transactions.

$\mathrm{H}_{3}$ : Dominant firm transactions will have higher costs per engineering change than non-dominant firm transactions.

\section{Transaction Cost Sharing}

Alternative work arrangements invoke many unique and interesting forms of dealing with the unknown. Williamson and Ouchi's (1981) framework of hard and soft contracting incorporates how organization's deal with uncertainty of partner behavior and intent. Partner opportunism inserts uncertainty into the economic trading relationship. Partners in an alternative work arrangement recognize this uncertainty and attempt to assign responsibility for this uncertainty, and the potential opportunism created by this uncertainty, by negotiating and committing to a cost-sharing formula before the contract is signed. The cost-share formula determines what percentage of cost overruns will be paid for by the buyer and seller in the contract. Cost-sharing formulas vary widely and are unique to each transaction. Typical costsharing formulas are stated in numerical terms. For instance, an " $85 / 15$ " ratio means that the seller will pay $85 \%$ of cost overruns on the contract and the buyer will pay $15 \%$. Table 2 summarizes the differences along critical transaction cost dimensions.

Table 2: Critical Dimensions Of Transaction Cost Theory In Terms of Opportunism

\begin{tabular}{|l|c|c|}
\hline Characteristics and Dimensions & Markets & Hierarchies \\
\hline Control & Limited & Maximized \\
\hline Production Costs & Low & Low \\
\hline Transaction Costs & High & High \\
\hline Coordination & Low & High \\
\hline Detail & Low & High \\
\hline Amount of Policy \& Provisions & Low & \\
\hline
\end{tabular}


Given a dominant firm's ability to indirectly increase contract costs, the dominant firm should also be able to get more favorable cost-sharing terms by paying less for cost overruns. The fourth hypothesis is based on the logic that the non-dominant organization will have less favorable cost-sharing terms compared to their dominant firm partner:

$\mathrm{H}_{4}$ : Dominant firms will share less in cost overruns compared to non-dominant firms.

\section{METHOD}

\section{Data Collection and Analysis}

Completed R\&D contract files were retrieved from the United States Air Force Material Command (AFMC) located at Wright-Patterson Air Force Base in Dayton, Ohio, USA as our primary source of data to test the seven hypotheses. AFMC serves as the primary center for the development and procurement of weapon systems by the Air Force. AFMC works in conjunction with other Air Force organizations to determine what needs exist and how to proceed in designing, developing and producing new weapons systems. After the needs analysis is conducted and the general requirements of a system are understood, AFMC negotiates with a government contractor to develop and produce the weapon system. Contracts are considered completed when a weapon system has been delivered to the Air Force. Files on completed contracts contain all legal, management, and performance data of the $\mathrm{R} \& \mathrm{D}$ transaction. Thus, these files contain rich sources of data regarding how alternative work arrangements were structured and managed ${ }^{1 .}$

Two hundred thirty nine contracts with complete data were selected at random from a population of 957 closed contracts that were awarded between 1974 and 1996 (the complete contract database). These contracts were completed by 113 firms. A review of contract characteristics revealed that the majority of contracts were from 5 months to 270 months in length with a mean contract duration time of 61.39 months, and the value of the contracts included in the sample ranged from $\$ 25,500$ to approximately $\$ 2.3$ billion.

\section{Grouping of Dominant and Non-Dominant Firms}

The size of the contract was used to measure whether a firm was dominant or not for a particular transaction (Drew \& Skitmore, 1997; Palazola \& Campbell, 1988). To code the firms as dominant or non-dominant, we reviewed the distribution of dollars per contract and grouped the firms based on the mean contract value of our database of $\$ 58,699,435$. Specifically, all the firms that had completed a contract with a value equal to or greater than the mean of $\$ 58,699,435$ were coded as dominant. Supporting theory discussed earlier, sometimes organizations were both dominant and non-dominant in our database depending on the particular transaction. Firms below $\$ 58,699,435$ were coded as non-dominant for a transaction. Of the 113 firms in this random sample, 14 firms completed contracts with a final contract cost equal to or above the mean, and thus were classified as dominant firms. In total, these 14 firms completed 92 contracts. Additionally, 99 firms completed 147 contracts with a cost that was lower than the mean and thus were coded as non-dominant. The small number of firms $(n=14)$ that were classified as dominant serves as a reminder of the uniqueness of being able to wield economic power-dominant firms repeatedly extend their dominance with partner firms.

\section{Analytic Approach}

Given the four hypotheses based on identifying significant differences between two types of firm transactions (dominant and non-dominant), the analytic approach selected was analysis of variance (used to test Hypotheses 1 and 4) and analysis of covariance (used to test Hypotheses 2 and 3). The variables analyzed for each transaction are included in Appendix A as adapted from Adler, Scherer, Barton and Katerberg (1998).

For each case, an analysis of variance test was performed to test for differences in means between dominant and non-dominant firms. Analysis of variance allowed us to model with unequal variances since the variances for the two groups were significantly different. Contracts were randomly selected for this study. While our sample consisted of a total

1 Please contact the author for a summary of federal contracting in the aerospace industry 
of 239 transactions, 91 contracts were associated with dominant firms and 148 were non-dominant. Out of the 113 firms in our sample, 14 organizations turned out to be dominant and 99 non-dominant. Since F-Tests done to support this analysis were dependent on the degrees of freedom, our analysis resulted in an error degrees of freedom of 112. The effects of a specific time influencing the data was therefore limited since both groups included data evenly distributed across the time of study. Type of transaction, or contract type, was controlled for in Hypotheses 2 and 3 because these hypotheses dealt with the rate of change in the alternative work arrangement that could differ based solely on the type of arrangement used.

\section{Results}

Table 3 presents the correlations among the dependent variables used in the study. As the table shows, the variables are not highly correlated with one another with the exception of engineering changes and cost growth. However, this was expected given that engineering changes usually reflect additional work outside the scope of the contract that leads to cost growth. While some engineering changes can be minor in character, like changing the address of payment for the partner, other changes can take on extraordinary costs for both buyer or seller.

Table 3: Correlations among dependent variables used in this study

\begin{tabular}{|l|c|c|c|c|c|}
\hline & $\begin{array}{c}\text { \# of Eng. } \\
\text { Changes }\end{array}$ & $\begin{array}{c}\text { Cost of Eng. } \\
\text { Changes }\end{array}$ & Share ratio & Time Increase & Cost Growth \\
\hline Nu. of Eng. Changes & 1.00 & & & & \\
\hline Cost of Eng. Changes & 0.38 & 1.00 & & & \\
\hline Cost-Sharing Ratio & 0.12 & 0.08 & 1.00 & & \\
\hline Schedule Growth & 0.47 & 0.16 & 0.29 & 1.00 & \\
\hline Cost Growth & 0.40 & 0.97 & 0.08 & 0.17 & 1.00 \\
\hline
\end{tabular}

$\mathrm{n}=239$

For Hypothesis 1, F tests revealed a significant difference in cost growth $\left(\mathrm{F}_{1,112}=12.34, \mathrm{p}<.01\right)$, schedule increases $\left(\mathrm{F}_{1,112}=15.99, \mathrm{p}<.01\right)$, and number of engineering changes $\left(\mathrm{F}_{1,112}=19.49, \mathrm{p}<.01\right)$ between types of transaction (dominant vs non-dominant). These tests show that even though both types of transactions (dominant or non-dominant) had cost increases $(\mathrm{dom}=\$ 42,985,572.00$; non-dom $=\$ 1,214,101.90)$, schedule increases (dom $=51.08$ months; non-dom $=25.69$ months), and engineering changes ( $\mathrm{dom}=53$ changes; non-dom $=36$ changes) throughout the duration of the transaction, dominant firm transactions had significantly higher changes than non-dominant transactions. These results are shown in Table 4.

Table 4: Results for Hypothesis 1a, 1b, and 1c

\begin{tabular}{|c|c|c|c|c|c|c|}
\hline & \multicolumn{2}{|c|}{ Cost growth } & \multicolumn{2}{|c|}{ Schedule increases } & \multicolumn{2}{|c|}{ Num. of eng. changes } \\
\hline & $\mathbf{F}$ & Group Mean & $\mathbf{F}$ & Group Mean & $\mathbf{F}$ & Group Mean \\
\hline Hypothesis $1^{\mathrm{a}}$ & $12.34^{*}$ & & $15.99^{*}$ & & $19.49^{*}$ & \\
\hline Dominant transactions & & $42,985,572.0$ & & 51.08 & & 53.15 \\
\hline Non-Dominant transactions & & $1,214,101.9$ & & 25.69 & & 36.89 \\
\hline
\end{tabular}

$* \mathrm{p}<.01$

${ }^{\mathrm{a}}$ For the dominant group, $\mathrm{n}=92$; for the non-dominant group, $\mathrm{n}=147$

Tests also show support for Hypotheses 2 and 3. Hypothesis 2 tested the rate of an arrangement's cost growth revealed a significant difference in slopes between both groups $(F=17.68, p<.0001)$. This test shows that even though the final transaction cost increases as the transaction time increases, the rate of transaction cost increase is significantly higher for transactions made by dominant firms $(\$ 597,953)$ than for transactions done by non-dominant firms $(\$ 34,276)$. These results are presented in Table 5. 
Table 5: Results for Hypothesis 2

\begin{tabular}{|c|c|c|}
\hline & Beta_hat & F-Value \\
\hline Non dominant $^{\mathrm{b}}$ & 34,276 & \\
\hline Dominant $^{\mathrm{b}}$ & 597,953 & $17.68^{\mathrm{a}}$ \\
\hline Interaction $^{\mathrm{a}}$ & & \\
\hline
\end{tabular}

${ }^{\mathrm{a}} \mathrm{p}<.0001$

${ }^{\mathrm{b}}$ For the dominant group, $\mathrm{n}=92$; for the non-dominant group, $\mathrm{n}=147$

Hypothesis 3, which tested transactions' cost of engineering changes as a function of number of engineering changes for each transaction type also revealed a significant difference in slopes between both groups $(F=4.52, p<.05)$. This test shows that, regardless of transaction type, as the total number of engineering changes grows, the total cost of engineering changes also grows. However, the cost increase per engineering change is significantly higher in transactions made by dominant firms $(\$ 337,115.00)$, than in transactions made by non-dominant firms $(\$ 116,927.00)$. These results are presented in Table 6.

Table 6: Results for Hypothesis 3

\begin{tabular}{|l|c|c|}
\hline & Beta_hat & F-Value \\
\hline Non dominant $^{\mathrm{b}}$ & 116,927 & \\
\hline Dominant & & \\
\hline Interaction & 337,115 & $17.68^{\mathrm{a}}$ \\
\hline
\end{tabular}

${ }^{\mathrm{a} p}<.0001$

${ }^{\mathrm{b}}$ For the dominant group, $\mathrm{n}=92$; for the non-dominant group, $\mathrm{n}=147$

Hypothesis 4 tested for significant differences in the cost-overrun share levels between dominant and nondominant groups. F-tests revealed a significant difference in cost-overrun share levels $\left(\mathrm{F}_{1,112}=32.86, \mathrm{p}<.0001\right)$. The test shows that transactions made by dominant firms involve, on average, a cost-overrun share of $76.16 \%$, while transactions made by non-dominant firms only involve a cost-overrun share level of $32.86 \%$. Thus, it is clear that in transactions made with dominant firms, the buyer holds a significantly higher amount of economic risk than the dominant firm. These results are shown in Table 7.

Table 7: Results for Hypothesis 4

\begin{tabular}{|l|c|c|}
\hline \multicolumn{2}{|c|}{} & Cost-Overrun Share \\
\hline \multicolumn{2}{|c|}{ Froup Mean } \\
\hline Hypothesis 4 & \multicolumn{1}{|c|}{ F } & 76.16 \\
\hline Dominant transactions & $32.86^{*}$ & 47.89 \\
\hline Non-Dominant transactions & & \\
\hline
\end{tabular}

$* \mathrm{p}<.0001$

${ }^{\mathrm{a}}$ For the dominant group, $\mathrm{n}=92$; for the non-dominant group, $\mathrm{n}=147$

\section{DISCUSSION}

Results supported the hypotheses of differences between dominant and non-dominant firms for all the variables tested. For instance, even though contracts made between the Air Force and dominant or non-dominant firms had higher actual costs than estimated costs, contracts made with dominant firms encompassed significantly higher increments- the rate of change was much higher than expected for dominant firms. Similarly, there were significant differences between the dominant and non-dominant contracts related to the increment in time needed to complete the contract. Dominant firms tended to draw out the partnership thereby controlling partner resources for longer periods of time. Finally, contracts made 
with dominant firms presented higher numbers of engineering changes and higher costs of these changes than contracts made with non-dominant firms.

The results support all the hypotheses related to dominant firms and opportunistic behavior that, ultimately, reinforce perceptions of distrust in the partnership organization. Furthermore, when we looked at both the increase in contract cost and the increase in contract time, it was found that the ratio of cost increase to time increase was significantly higher for the contracts made with dominant firms. When we analyzed both the engineering changes and subsequent increases in contract cost, we found that the increase in cost per engineering change was significantly higher for the contracts made with dominant firms. When you add the overrun-cost share variable we was found that contracts made with dominant firms were more likely to have less sharing of cost overruns meaning their partner, the United States Air Force, would have to pay for most of the cost increases. Contracts made with non-dominant firms on the other hand were more related to lower cost-overrun shares and more balanced cost-sharing.

In general, firms govern the development of technology differently as evidenced by the growing body of research in outsourcing and governance options (Barthelemy \& Adsit, 2003; Schilling \& Steensma, 2001). Most of these analyses have been at the firm-level of analysis and have provided clues as to how firm-level characteristics account for differences within industries. However, as suggested by Williamson (1985), there is a gray, mid-range set of governance choices between transactions within firms that are governed by organizational contracts that have been relatively abandoned. As discussed previously, there is ample evidence in the literature regarding the use of contracts to govern product innovation (Argyres, 1993; Crocker \& Reynolds, 1993) but little evidence regarding differences with regard to dominance effects in alternative work arrangements. Dominance measured in alternative work arrangement characteristics could be a key governance consideration in explaining how trading relationships vary (Teece, 1986).

The contract size determination borrows implications from the monopolistic analogy where firms control market conditions based on the size of their company in a particular industry. For instance, one example is where a large-sized contract ties up large amounts of vendor, or partner, resources as a proportion of the total business of the vendor or partner creating a strategic advantage for a partner in the contract relationship. Williamson (1985: 40) states that "monopoly supply is efficient where economies of scale are large in relation to the size of the market." If the contract size is large relative for a monopoly-like partnership, then large contracts may create inefficiencies in economic trading. Thus, the contract size determination is an important consideration with regard to managerial and economic trade-offs coordination, integration and flexibility in the ability to select or change economic trading partners. Contract size as a consideration in monopolistic-type work arrangements is an area ripe for future research and one that would contribute to our understanding of non-traditional modes of exchange.

\section{Implications for Practitioners}

The competitive implications of our results are profound. If dominant firms view contracts as a vehicle for manipulating a trading partner, then contract size should also be considered with regard to how a transaction, and accompanying contract, affects the competitive position of the firm. Barney (1995) and Stalk, Evans \& Shulman (1992) provide a useful argument that competitive viability rests on the development of strategic capabilities that are collective, cross-functional and smaller in focus. The ability to formulate and manage dominant and non-dominant firms based on transaction size that fit the characteristics of new technology developments is certainly a collective and cross-functional endeavor and could very well be a key strategic capability of firms in the future.

\section{Research Limitations and Directions}

Our study focused on government R\&D contracting in the aerospace industry and this may limit some of our conclusions. However, the dimensions that are associated with different contracts as operationalized in the current study can be found in commercial settings especially those in which the buyer cannot, or is restricted from, vertically integrate. Furthermore, even though the results presented seem to point to the fact that dominant firms take advantage of the Air Force and act opportunistically, the results found could have other explanations that can be discovered by analyzing in more detail the dynamics of the contractual relation. This study provides insight that might otherwise be left untouched- 
how perceived distrust could influence the development of alternative work arrangements.

From a methodological standpoint, a limitation of this study is related to the grouping of the firms in our sample into dominant and non-dominant. As explained previously, this grouping was split into halves based on the final contract cost for all the transactions in our sample. It is important to be cautious when doing a mean or median split because either one of these numbers may change dramatically if the sample size increases or changes. In order to avoid this from happening, researchers should always make sure to have a sample that is highly representative of the population.

Finally, it is possible that the characteristics of the transactions could have been affected by variables not considered in the analysis of the data. However, it was assumed that given the breath and depth of our sample, (contracts were randomly selected; ranged from 25 thousand to 2.3 billion dollar contracts; expanded over a period of 22 years; varied from 5 month long contracts to 270 month long contracts), it was not likely that the differences found between the groups were due to the special effect of special variables over specific transactions.

Comparisons between dominant and non-dominant firms also could be extended to the study of monopolistic trading implications in how contract requirements are written. Do dominant firms tie-up large amounts of nonrecombinable assets that inhibit relationships with other outsource providers? In other words, do dominant firms deliberately create barriers of entry, and thus competitive advantages for themselves, by using alternative work arrangements opportunistically? Or do complex contract requirements merely reflect the intraorganizational complexity suggested by Kim and Wilemon (2003) in a new product development.

Another direction for research is to study how specialized contractual requirements can be written to protect assets in the contractual exchange. Can contract requirements be formulated in such a way as to protect assets from opportunism in an exchange? Buyers and sellers both provide resources in contractual exchanges, some more than others. During the period of contractual enforcement, these resources become less likely to be used for other transactions thereby making their asset specificity extremely high for a given transaction. In a new technology development context, learning occurs through experimentation and adaptation meaning contract requirements tend to be less complete (Hedberg, 1981). How are large contracts structured to foster a balance between learning and constraints of time and cost? Clearly this line of research is ripe for study given the propensity of firms to seek out more external sources of information (Blenkhorn \& Noori, 1991; Liker \& Yu, 2000).

\section{CONCLUSION}

The differences between large-sized alternative work arrangements are distinct. Given that the use of outsourcing contracts is increasing, the risks associated with partnering are even greater in a hostage environment without consideration of how this relationship may affect long-term losses of information. R\&D collaborations exacerbate this phenomenon because future R\&D outsourcing becomes the more likely outcome when internal and organic capabilities become less likely to conduct work in-house. We hope that the results of this investigation will encourage future study of alternative work arrangements. Then we can more fully understand how governance options differ and how managers utilize organizational resources to meet future organizational and governance objectives.

\section{REFERENCES}

1. Adler, T. 2005. The swift trust partnership: A project management exercise investigating the effects of trust and distrust in outsourcing relationships. Journal of Management Education, 29 (5): 714-737.

2. Adler, T. 2000. An evaluation of the social perspective in the development of technical requirements. IEEE Transactions on Professional Communication, 43 (5): 17-25.

3. Adler, T., R. Scherer, S. Barton, and R. Katerberg. 1998. An empirical test of transaction cost theory: Validating contract typology. Journal of Applied Management Studies, 7 (2): 185-201.

4. Anson, C. 1988. Toward a multidimensional model of writing in the academic disciplines. In D.A. Jolliffe (Ed.), Advances in writing research, volume two: Writing in academic disciplines. Norwood, NJ: Ablex Publishing Corp. 
5. Argyres, N.S., 1993. Essays on Technology, Strategy and Organization. Unpublished doctoral dissertation, University of California, Berkeley.

6. Barney, J. 1995. Looking inside for competitive advantage. Academy of Management Executive, 9 (4): 49-62.

7. Barthelemy, J. \& Adsit, D., 2003. The seven deadly sins of outsourcing. Academy of Management Executive, 17(2): 87-101.

8. Benfratello, L. and Sembenelli, A. 2002. Research joint ventures and firm level performance. Research Policy, 31 (4): 493-507.

9. Blenkhorn, D. L. and Noori, A. H. 1991. What it takes to supply Japanese OEMs. Industrial Marketing Management, 19(1): 75-81.

10. Boswell, C. 2000. For Albany Molecular, proprietary technologies are key to success. Chemical Market Reporter, 258 (21): 29-35.

11. Business Week. 2006. The Future of Outsourcing. January 30, 2006.

12. Cheung, F. K. and Wang, X. 1994. Adjusted concavity and the output effect under monopolistic price discrimination. Southern Economic Journal, 60(4)4, 1048-1055

13. Crocker, K.J. and Reynolds, K.J., 1993. The efficiency of incomplete contracts: An empirical analysis of Air Force engine procurement. Rand Journal of Economics, 24 (1): 126-146.

14. D'Aveni, R. A. 1999. Strategic supremacy through disruption and dominance. Sloan Management Review, 40, $127-135$

15. Dannels, D. 2000. Learning to be professional. Journal of Business and Technical Communication, 14 (1): 5-37.

16. Drew, D. and Skitmore, M., 1997. The effect of contract type and size on competitiveness in bidding. Construction Management \& Economics, 15 (5), 469-489.

17. Evanchik, M. A. 1989. A transaction cost analysis of defense contracting. Doctoral Dissertation., University of Washington.

18. George, K. and Jacquemin, A. 1972. Dominant firms and Mergers. The Economic Journal, 102, 148-157

19. Geroski, P. and Jacquemin, A. 1984. Dominant firms and their alleged decline. International Journal of Industrial Organization, 2, 1-28

20. Hedberg, B. 1981. How organizations learn and unlearn. In Nystrom, P. and Starbuck, W. (Eds.), Handbook of Organizational Design, Vol. 1, New York: Oxford University Press.

21. Kim, J. and Wilemon, D. 2003. Sources and assessment of complexity in NPD projects. $R \& D$ Management, 33 (1): 16-30.

22. Kreps, D. and Wilson, R. 1980. On the chain-store paradox and predation: Reputation for toughness. GSB Research Paper No. 551, June, Stanford, CA.

23. Lacity, M. and Willcocks, L., 1998. An empirical investigation of information technology sourcing practices: Lessons from experience. MIS Quarterly, 22 (3): 363-408.

24. Liker, J. K. and Yu, Y-C. 2000. Japanese automakers, U.S. suppliers and supply-chain superiority. MIT Sloan Management Review, 42 (1): 81-93.

25. Odell, L. and Goswami, D. 1985. Writing in Nonacademic Settings. New York: Guilford Press.

26. Paladino, M., Bates, H., and da Silveira, G. 2002. Using a customer-focused approach to improve quality across the value chain: The case of Siderar. Total Quality Management, 13 (5): 671-683.

27. Palazola, R.L. and Campbell, M., 1988. The secondary market: ahead to more futures. Mortgage Banking, 48 (7): 23-26.

28. Pass, C. and Lowes, B. 1992. Control of dominant firms in the UK and EC. Management Decision, 30, 3845.

29. PM Network. 2004. Digging deep. PM Network, August: 1.

30. Riordan, M. H. (1998). Anticompetitive Vertical Integration by a Dominant Firm. The American Economic Review, 88, 1232-1248

31. Roulac, S. E. 2000. Property Markets, Monopolies \& Microsoft. Source. Real Estate Issues. 25 (3), 21- 32.

32. Schilling, M. and Steensma, H., 2001. The use of modular organizational forms: An industry-level analysis. Academy of Management Journal, 44(6): 1149-1169.

33. Schoenwald, S. M. 1997. Regulating competition in the interexchange telecommunications market: The dominant/nondominant carrier approach and the evolution of forbearance. Federal Communications Law 
Journal. 49(2), 23-34

34. Solow, R. (1998). Monopolistic competition and macroeconomic theory. Cambridge University Press: Cambridge

35. Stalk, G., Evans, P., and Shulman, L. 1992. Competing on capabilities: The new rules of corporate strategy. Harvard Business Review, 70 (2): 57-70.

36. Stinchcombe, A.L., 1985. Contracts as hierarchical documents. In: A.L. Stinchcombe and C.A. Heimer (Eds.), Organizational Theory and Project Management. Norwegian University Press, Oslo, Norway, 361 pp.

37. Teece, D., 1986. Profiting from technological innovation: Implications for integration, collaboration, licensing and public policy. Research Policy, 15: 285-305.

38. Williamson, O.E., 1975. Markets and Hierarchies, Analysis and Antitrust Implications: A Study in the Economics of Internal Organization. Free Press, New York, 286 pp.

39. Williamson, O.E., 1985. The Economic Institutions of Capitalism: Firms, Markets, Relational Contracting. Free Press, New York, $450 \mathrm{pp}$.

40. Williamson, O.E., and Ouchi, W. 1981. The markets and hierarchies program of research: Origins, implications, prospects. In W. Joyce \& A. Van de Ven (Eds.), Organizational Design. New York: Wiley.

41. Yang, S. P. 2002. Identifying a dominant firm's market power among sellers of a homogeneous product: An application to Alcoa. Applied Economics, 34, 1411-1420

42. Zuckerman, D. and Higgins, M. 2002. Optimizing cross-organizational team performance and management. Pharmaceutical Technology North America, 26 (6): 76-80.

\section{APPENDIX A}

\section{Operational Definitions for Transaction Cost Measures}

1. The estimated time needed to complete the contract in months. This is the time in which the seller agrees to finish the work specified in the contract at the time at which the contract is signed.

2. The actual time needed to complete the contract in months. This is the actual time that the seller needed to complete the work specified in the contract.

3. The estimated cost of the contract in dollars. This is the estimated amount of money that the buyer agrees to pay the seller in order to complete the contract. This cost is agreed by both parties when the contract is signed.

4. The actual cost of the contract in dollars. This is the actual amount of money that the buyer pays the seller once the contract is completed.

5. Number of engineering changes: this variable refers to the number of engineering changes made once the contract has been signed which are necessary to complete the original contract.

6. Cost of engineering changes: this variable refers to the total cost of the engineering changes made once the contract has been signed which are necessary to complete the original contract.

7. Overrun-cost level: This is the percentage of the total overrun-cost that the buyer agreed to pay in case the actual cost of the contract exceeds the estimated cost. 